\title{
Production of synthetic zeolites from lignite - calcareous Greek fly ashes and their potential for metals and metalloids retention
}

\author{
A. Moutsatsou ${ }^{1} \&$ V. Protonotarios ${ }^{2}$ \\ ${ }^{1}$ National Technical University of Athens, Laboratory of Inorganic and \\ Analytical Chemistry, Department of Chemical Engineering, Greece \\ ${ }^{2}$ National Technical University of Athens, Laboratory of Inorganic and \\ Analytical Chemistry, Department of Chemical Engineering, Greece
}

\begin{abstract}
The current state of the art focuses on the production of synthetic zeolites from lignite - calcareous fly ashes. The synthetic minerals are produced by the hydrothermal treatment of Greek fly ashes originating from Ptolemais and Megalopolis Power Plants in Greece. The products are examined in terms of their mineralogical composition, for the formation of known zeolites, morphology, thermal behavior, cation exchange capacity, $\mathrm{pH}$, porosity and specific surface area. Zeolitic products, along with untreated fly ash, are investigated for their potential of retaining heavy metals from liquid wastes. The mechanisms of metal retention by zeolites in artificial solutions including lead, zinc, copper, arsenic and cadmium were examined. Solutions including the same pollutants, mobilized from a contaminated soil, utilizing selected solvents were produced. Results revealed the capability of zeolitic materials and fly ashes to retain metals in significant concentrations. Furthermore, a number of different retention mechanisms are developed, including ion exchange, surface adsorption and precipitation of metals.
\end{abstract}

Keywords: fly ash, zeolites, metals, metalloids, retention mechanisms.

\section{Introduction}

Fly Ash (FA) is a by product derived from the combustion of coal or lignite, mainly in electric power stations. More than 11.5 million tons of lignite fly ash is 
produced annually in Greece [1]. Throughout EU, a small percentage (less than $30 \%$ ) of the produced FA is used for lignite quarries reclamation, in cement industry as cement additive, for road construction, in structural materials and as a soil additive [2]. Nevertheless, the largest amount of the waste product is directly discharged into ponds and landfills. Possible application for the effective consumption of FA could be the formation of zeolites. The particular process is similar to the formation of natural zeolites from volcanic deposits or other high Si-Al materials [3-5]. The main process from which zeolites can be naturally formed is through the influence of hot groundwater on the glass fraction of volcanic ash. In the laboratory, the activation solution is usually $\mathrm{NaOH}$ or $\mathrm{KOH}$ in different molarities and according to atmospheric or water vapor pressure, at a temperature $80-200^{\circ} \mathrm{C}$ and for 3 to $96 \mathrm{~h}$ different types of zeolites can be synthesized [3-9].

Metals and metalloids such as $\mathrm{Pb}, \mathrm{As}, \mathrm{Cu}, \mathrm{Zn}, \mathrm{Fe}$ and $\mathrm{Mn}$ are well known as a serious environmental hazard [10]. Intensive industrial activity has resulted in the accumulation of high concentrations of heavy metals and toxic elements in the environment, causing health, ecological and socio-economic problems [11]. New technologies in the area of environmental relief from metal pollution include the utilization of industrial by-products (fly ashes and slag) presenting high adsorption capacity with respect to metals [12] resulting to environmental and economical, benefits.

The current state of art focuses on the following topics:

1. Formation of zeolites from Greek FAs

2. Investigation of zeolitic materials for a number of critical attributes in the direction of optimum metal and metalloid retention

3. Application of the zeolitic materials and the untreated FAs for metals and metalloids retention, under acidic conditions, utilizing both artificial and real polluted solutions.

\section{Materials and methods}

\subsection{Zeolites synthesis}

Ptolemais FA (PFA) and Megalopolis FA (MFA) underwent an alkaline hydrothermal treatment at $90^{\circ} \mathrm{C}$, using $\mathrm{NaOH} 1 \mathrm{M}$ as an activation solution, in a $1 \mathrm{~L}$ stainless steel reactor. The incubation time was set at $24 \mathrm{~h}$, stirring at $150 \mathrm{rpm}$. Then, the mixture was filtered with a $0.45 \mu \mathrm{m}$ paper, leached with water until no $\mathrm{NaOH}$ was detected and the collected solid residue was dried at $40^{\circ} \mathrm{C}$ for $24 \mathrm{~h}$. The final solid product, along with the FAs, was subjected to XRD analysis and SEM investigation for identification of known zeolites. The $\mathrm{pH}$, Cation Exchange Capacity (CEC), Specific Gravity and Specific Surface Area (SSA) of the FAs and the zeolitic products were also determined. Two different solution/FA ratios were examined for each of PFA and MFA. In Table 1 the four synthesized materials are presented. 
Table 1: $\quad$ Alkali activation of Greek $\mathrm{FA}_{\mathrm{s}}$ under $90^{\circ} \mathrm{C}, \mathrm{NaOH} 1 \mathrm{M}$.

\begin{tabular}{|c|c|c|c|}
\hline FA Origine & $\begin{array}{c}\text { FA/Solution Ratio } \\
\left(\mathrm{g} \mathrm{L}^{-1}\right)\end{array}$ & 2.1.1 & Product Code \\
\hline Ptolemais & 50 & & $\mathrm{ZP}_{50}$ \\
\hline Ptolemais & 100 & & $\mathrm{ZP}_{100}$ \\
\hline Megalopolis & 50 & & $\mathrm{ZM}_{50}$ \\
\hline Megalopolis & 100 & & $\mathrm{ZM}_{100}$ \\
\hline
\end{tabular}

\subsection{Metals and metalloids retention from artificially polluted sample}

Synthetic materials were examined for their potential of retaining pollutants from artificially polluted solutions. In particular, a hydrochloric acid base solution with concentrations of $\mathrm{Pb}, \mathrm{As}, \mathrm{Cd}, \mathrm{Cu}, \mathrm{Zn}, \mathrm{Fe}$ and $\mathrm{Mn}$ was prepared. The pollutants concentrations were selected so as to be similar to that derived from the effect of $\mathrm{HCl}$ to contaminated soil samples (see 2.3). Metal and metalloids concentrations are illustrated in Table 2. Solutions were mixed in a solid to liquid ratio of $20 \mathrm{~g} \mathrm{~L}^{-1}$ with the zeolitic materials and the FAs.

\subsection{Metals and metalloids retention from contaminated soil}

Soil sample was collected from a former mining - metallurgical site in the city of Lavrion, Greece. Pollution is typical of a heavy mining - metallurgical industry and consists mainly of slag, sulphur compounds and oxidized phases, with an extremely complicated mineralogy. After mobilization of metal and metalloid content by $1 \mathrm{M} \mathrm{HCl}$, further adsorption of the pollutants on synthesized zeolites and FAs was examined. The chemical composition of the $\mathrm{HCl}$ extraction solution, concerning the selected pollutants, is shown in Table 2. For retention experiments, a solid to liquid ratio of $20 \mathrm{~g} \mathrm{~L}^{-1}$ was used.

Table 2: $\quad$ Concentrations of artificial and soil solutions.

\begin{tabular}{ccc}
\hline Element & $\begin{array}{c}\text { Concentration in } \\
\text { artificial sample (ppm) }\end{array}$ & $\begin{array}{c}\text { Concentration in soil } \\
\text { sample (ppm) }\end{array}$ \\
\hline $\mathbf{F e}$ & 2000 & 2500 \\
$\mathbf{C u}$ & 75 & 75 \\
$\mathbf{Z n}$ & 1000 & 1375 \\
$\mathbf{M n}$ & 100 & 100 \\
$\mathbf{P b}$ & 800 & 844 \\
\hline $\mathbf{A s}$ & 150 & 176 \\
\hline
\end{tabular}

\section{Results and discussion}

\subsection{Zeolites synthesis}

$\mathrm{FA} / \mathrm{NaOH}=\mathbf{5 0} \mathbf{g ~ L ~}^{\mathbf{- 1}}$ for PFA, XRD pattern and SEM graphs, confirm an essential dissolution of the predominant fly ash phases (alumino-silicate glass, 
quartz) and the formation of NaP1 (tabular crystals) and NaP Zeolites ("blade" crystals) (Table 3). The semi-quantitative estimation of zeolite content is 30$35 \%$. Results are similar for MFA and $\mathrm{s} / 1=\mathbf{5 0} \mathbf{g ~ L ~}^{\mathbf{- 1}}$. In case of MFA, the zeolitization yield is higher, fluctuating between 40 and $45 \%$. This fact was rather expected, due to the lower calcium and the higher silica content of the particular FA $[5,10]$.

Table 3: $\quad$ Zeolites identified from XRD patterns.

\begin{tabular}{|c|c|c|c|c|}
\hline Zeolite & $\mathbf{Z P}_{50}$ & $\mathbf{Z P}_{100}$ & $\mathbf{Z M}_{50}$ & $\mathbf{Z M}_{100}$ \\
\hline NaP1 & + & & + & \\
\hline NaP & + & + & + & + \\
\hline \multicolumn{5}{|l|}{ Herschelite } \\
\hline Tobermorite & & & & + \\
\hline Hydroxy-cancrinite & & & & + \\
\hline Hydroxy-sodalite & & & & + \\
\hline
\end{tabular}

When s/l increases further to $100 \mathbf{g ~ L}^{-1}$ for PFA NaP zeolite is detected $(15-20 \%)$ while formation of NaP1 is insignificant. Due to the increase of FA with respect to $\mathrm{NaOH}$, a significant dissolution of the initial FA phases is not achieved. $\mathrm{SiO}_{2}$ and $\mathrm{CaCO}_{3}$ remain almost intact and no significant crystallization is taking place. In case of MFA, in addition to NaP, Tobermorite, Hydroxycancrinite and Hydroxy-sodalite are detected and their semi-quantitative percentage is estimated to $10-15 \%$.

The $\mathbf{p H}$ is slightly higher for the greatest s/l ratio, for both FAs (Table 4). After the zeolitization process, the initial CEC of PFA and MFA (0.030 and $\left.0.023 \mathrm{meq} \mathrm{g}^{-1}\right)$ increase significantly, reaching a maximum for $\mathrm{ZP}_{50}$ and $\mathrm{ZM}_{50}$ (0.870 and $\left.1.164 \mathrm{meq}^{-1}\right)$ (Table 4). However, CEC decreases with further increase of $\mathrm{s} / 1\left(100 \mathrm{~g} \mathrm{~L}^{-1}\right)$ for MFA. That is rather normal, since for the highest $\mathrm{FA} / \mathrm{NaOH}$ ratio, the pure zeolite content of the products is lower. For $\mathrm{s} / \mathrm{l}$ up to $50 \mathrm{~g} \mathrm{~L}^{-1}$, experimental products from MFA present higher CEC than the respective from $\mathrm{PFA}$, but for higher $\mathrm{FA} / \mathrm{NaOH}$ ratio, $\mathrm{ZP}_{100}$ excel $\mathrm{ZM}_{100}$ with respect to their CEC. It should be mentioned that, the morphology of $\mathrm{ZP}_{100}$ and $\mathrm{ZM}_{100}$, seems promising for probable use of the aforementioned materials as adsorbents.

Hydrothermal treatment of FA may have conflicting impacts on SG of the final products (Table 4). As long as the $\mathrm{NaOH}$ solution penetrates the cenospheres, allows the escape of the trapped air and thus increasing the SG [12]. Nevertheless, as the zeolitization process evolves, the subsequent crystallization of the experimental products yields to a larger pore volume, thus the $\mathrm{SG}$ decreases. In the present case, $\mathrm{SG}$ decreases as $\mathrm{PFA} / \mathrm{NaOH}$ ratio increases, while, in case of MFA, SG presents a minimum for $\mathrm{ZM}_{100}$. 
The SSA of PFA increases up to $400 \%$ for $\mathrm{s} / 1=50 \mathrm{~g} \mathrm{~L}^{-1}$ and then slightly decreases with further rise of PFA/NaOH ratio (Table 4). Results are even better for MFA, since SSA increases, with respect to the raw material, amounts to $800 \%$. Nevertheless, there is a significant recession of SSA value for $Z_{100}$. From the aforementioned results it is obvious that the alkali activation of the $\mathrm{FA}_{\mathrm{s}}$ results in decreasing the particle size of the raw materials. The latter phenomenon is probably attributed to the dissolution (etching) of the FA cenospheres and the subsequent exposure of their inner surface [13]. As it was expected, SSA best results are obtained for $Z_{50}$ and $Z \mathrm{P}_{50}$ for which the maximum zeolitization yields (i.e. the best dissolution of the cenospheres) are observed.

\subsection{Metals and metalloids retention from artificially polluted sample}

Retention yields seems to be very high as it is illustrated in Table 5 for PFA substrates, especially in case of $\mathrm{Mn}, \mathrm{Cu}$ and $\mathrm{Pb}$. Slightly lower retention yields are observed in case of As, while significantly lower retention is achieved for Fe and $\mathrm{Zn}$. When MFA substrates are used, $\mathrm{Mn}, \mathrm{Cu}$ and $\mathrm{Pb}$ present a very satisfactory retention, while Fe retention is lower than in case of PFA substrates. In all cases, the capability of untreated FAs for pollutants retention is ameliorated with respect to $\mathrm{Fe}, \mathrm{Zn}, \mathrm{Pb}$ and $\mathrm{As}$, while zeolitic materials and $\mathrm{FAs}$ are retaining the total quantity of $\mathrm{Cu}$ and $\mathrm{Mn}$ present in the artificial solution.

Table 4: $\quad$ Selected properties of FAs and Zeolitic materials.

\begin{tabular}{ccccc}
\hline & $\mathbf{p H}$ & $\mathbf{C E C}\left(\mathbf{m e q} \mathbf{g}^{\mathbf{- 1}}\right)$ & $\mathbf{S G}\left(\mathbf{g ~ m}^{\mathbf{1}}\right)$ & $\mathbf{S S A}\left(\mathbf{g ~ m}^{\mathbf{2}}\right)$ \\
\hline PFA & 9.9 & 0.03 & 2.6 & 5.1 \\
MFA & 10.1 & 0.02 & 2.7 & 7.4 \\
$\mathbf{Z P}_{\mathbf{5 0}}$ & 11.8 & 0.87 & 2.5 & 20.3 \\
$\mathbf{Z P}_{\mathbf{1 0 0}}$ & 12.0 & 0.81 & 2.2 & 17.6 \\
$\mathbf{Z M}_{\mathbf{5 0}}$ & 10.0 & 1.16 & 2.3 & 60.7 \\
\hline $\mathbf{Z M}_{\mathbf{1 0 0}}$ & 10.5 & 0.51 & 2.4 & 16.4 \\
\hline
\end{tabular}

Table 5: $\quad$ Percentage retention pollutants from artificially pollutant sample.

\begin{tabular}{lllllll}
\hline & Fe & $\mathbf{C u}$ & $\mathbf{Z n}$ & $\mathbf{M n}$ & $\mathbf{P b}$ & $\mathbf{A s}$ \\
$\mathbf{Z P}_{\mathbf{5 0}}$ & 64.8 & 100.0 & 65.4 & 100.0 & 81.2 & 84.1 \\
$\mathbf{Z P}_{\mathbf{1 0 0}}$ & 67.1 & 100.0 & 71.2 & 100.0 & 79.4 & 80.2 \\
PFA & 62.5 & 100.0 & 58.4 & 100.0 & 70.3 & 71.7 \\
$\mathbf{Z M}_{\mathbf{5 0}}$ & 47.0 & 100.0 & 57.3 & 100.0 & 82.2 & 80.5 \\
$\mathbf{Z M}_{\mathbf{1 0 0}}$ & 51.4 & 100.0 & 59.1 & 100.0 & 80.1 & 82.1 \\
MFA & 47.5 & 100.0 & 45.2 & 100.0 & 77.4 & 74.3 \\
\hline
\end{tabular}




\subsection{Metals and metalloids retention from contaminated soil}

In Table 6, the respective retention yields of the zeolitic materials, with respect to soil pollutants, are presented. As it was expected results are significantly lower than those obtained for the artificially polluted sample, with the exception of As retained on $\mathrm{ZP}_{50}$. Pure zeolites are expected to retain metals mainly through an ion - exchange mechanism. It should be mentioned that, for purposes of effective retention of metals and metalloids, the non-complete transformation of FA to zeolites is preferable. This is due to the fact that the portion of FA that has not been converted to zeolite, may trigger additional retention mechanisms such as precipitation or surface adsorption. Another important advantage concerning the presence of unconverted FA is the capability of further stabilization/solidification of the pollutants on the substrates [13]. Results presented in Table 6 are quite satisfactory, bearing in mind the extreme pollution load of the washing solution and the great variety of metals and metalloids compounds present. It is obvious that the results between the different substrates, verify the triggering of a variety of retention mechanisms. The latter are depended, not only on the zeolitic material, but also on the pollutant - solvent substrate interaction. Finally, with the exception of $\mathrm{Zn}$ and $\mathrm{Pb}$, there is a significant amelioration of the retention capacity of the FAs, after their hydrothermal treatment.

Table 6: Percentage retention of soil pollutants on Zeolitic materials and Fas.

\begin{tabular}{ccccccc}
\hline & Fe & Cu & Zn & Pb & As & Mn \\
\hline ZP $_{\mathbf{5 0}}$ & 45.3 & 25.7 & 19.6 & 27.7 & 90.3 & 68.8 \\
$\mathbf{Z P}_{\mathbf{1 0 0}}$ & 44.6 & 30.5 & 23.7 & 18.8 & 28.5 & 32.5 \\
PFA & 5.2 & 6.1 & 22.7 & 18.3 & 8.2 & 7.4 \\
$\mathbf{Z M}_{\mathbf{5 0}}$ & 50.8 & 42.8 & 27.2 & 25.7 & 24.4 & 40.2 \\
$\mathbf{Z M}_{\mathbf{1 0 0}}$ & 42.4 & 33.2 & 25.3 & 24.2 & 22.7 & 42.6 \\
\hline MFA & 4.8 & 15.2 & 18.2 & 21.2 & 7.1 & 12.7 \\
\hline
\end{tabular}

\section{Conclusions}

Two Greek $\mathrm{FA}_{\mathrm{s}}$ (Ptolemais FA and Megalopolis FA) were subjected to hydrothermal treatment for purposes of zeolites production. The best FA/ NaOH ratio for both quantitative and monomineral synthesis is spotted at $50 \mathrm{~g} \mathrm{~L}^{-1}\left(\mathrm{ZP}_{50}\right.$ and $\mathrm{ZM}_{50}$ ) for which $\mathrm{NaP} 1$ and $\mathrm{NaP}$ zeolites are formed in a 30-45\%. Both Cation Exchange Capacity and Specific Surface Area of the experimental products are very improved with respect to the original $\mathrm{FA}_{\mathrm{s}}$ and $\mathrm{ZM}_{50}$ presents the better results. Experimental products, along with untreated FAs were examined for their capacity in retaining heavy metals and metalloids from contaminated and artificially polluted samples, under acidic conditions. Results were excellent with respect to artificially polluted samples, with the zeolitic materials present improved retention yields compared to the untreated FAs. 
Relatively low, but satisfactory retention capacity was illustrated for soil polluted sample, with the synthetic materials being considerably more effective with respect to metals and metalloids retention, than the raw FAs. The presence of a significant unconverted portion of FA in all zeolitic materials, indicate the capability of developing different retention mechanisms, including, except from the ion-exchange, precipitation and surface adsorption. The latter could be critical in view of further stabilization/solidification of the retained pollutants.

\section{References}

[1] Moutsatsou A., Stamatakis M. Hatzitzotzia K., Protonotarios, V. (2005): The utilization of Greek Ca-rich and Ca-Si-rich fly ashes in the production of synthetic minerals. Fuel, Vol .85/5-6 pp. 657-663.

[2] Querol X., Alastuey A., Fernadez-Turiel L. J., Lopez-Soler A. (1995): Synthesis of zeolites by alkaline activation of ferro-aluminus fly ash. Fuel, Vol. 74, pp. 1226-1231.

[3] Steenbruggen G., Hollman G. G (1997). The synthesis of zeolites from fly ash and the properties of the zeolite products. Journal of Geochemical Exploration, Vol. 62, pp. 305-309.

[4] Hollman G. G, Steenbruggen G., Jourkovicova J. V. (1999): A two step process for the synthesis of zeolites from coal fly ash. Fuel, Vol. 78, p. 1225-1230.

[5] Querol X., Moreno N., Umana C. J., Alastuey A., Hernadez E. J., LopezSoler A., Plana F. (2002): Synthesis of zeolites from coal fly ash: an overview. Coal Geology, Vol. 50, p. 413-423.

[6] Norihiro M., Yamamoto H., Shibata J. (2002): Mechanism of zeolite synthesis from coal fly ash by alkali hydrothermal reaction. International Journal of Mineral Processing, Vol. 64, pp. 1-17.

[7] Shih W. H., Chang H. L. (1996). Conversion of fly ash into zeolites for ion exchange applications. Materials Letters, Vol. 28, pp. 263-268.

[8] Albert R. B., Cheetham K. A., Stuart, J. A Adams C. J. (1998). Investigations on $\mathrm{P}$ zeolites: synthesis, characterization and structure of highly crystalline low-silica NaP. Microporous and Mesoporous Materials, Vol. 21, p. 133-142.

[9] Tanaka S., Sakai Y., Hino R. (2002). Formation of Na-A and Na-X zeolites from waste solutions in conversion of coal fly ash to zeolites. Materials Research Bulletin, Vol. 37, p. 1873-1884.

[10] Nael, C. N., Bricka, M. R., Chao, A. C., 1997. Evaluating acids and chelating agents for removing heavy metals from contaminated soils. Environ. Prog. 16, 274-280.

[11] Maiz I., Esnaola V.M., Millan E. (1997). Evaluation of heavy metal availability in contaminated soils by a short sequential extraction procedure. The Science of the Total Environment, Vol. 206, pp. 107- 115.

[12] A. Moutsatsou, A. Karathanasis \& V. Protonotarios (2004): Remediation of soils polluted by industrial activities utilizing hydrothermally treated calcareous fly ashes. $2^{\text {nd }}$ International Conference on Waste Management 
56 Waste Management and the Environment III

and the Environment, Section 6: Environmental Effects and Remediation, pp. 283-291, Rhodes, Greece.

[13] A. Moutsatsou M. Gregou, M. Liokalou, D. Matsas and Protonotarios V (2003): Mobilization of metals and metalloids from contaminated soil and readsorption on synthesized zeolites and zeolite-fly ash mixtures. $8^{\text {th }}$ International Conference on Environmental Science and Technology, Lemnos, Greece, Vol. A, pp. 642-649. 